\title{
Vision, Knowledge, and Assertion*
}

John Turri

Philosophy Department and Cognitive Science Program

University of Waterloo

200 University Avenue West

Waterloo, Ontario N2L3G1

Canada

john.turri@gmail.com

Abstract: I report two experiments studying the relationship among explicit judgments about what people see, know, and should assert. When an object of interest was surrounded by visibly similar items, it diminished people's willingness to judge that an agent sees, knows, and should tell others that it is present. This supports the claim, made by many philosophers, that inhabiting a misleading environment intuitively decreases our willingness to attribute perception and knowledge. However, contrary to stronger claims made by some philosophers, inhabiting a misleading environment does not lead to the opposite pattern whereby people deny perception and knowledge. Causal modeling suggests a specific psychological model of how explicit judgments about perception, knowledge, and assertability are made: knowledge attributions cause perception attributions, which in turn cause assertability attributions. These findings advance understanding of how these three important judgments are made, provide new evidence that knowledge is the norm of assertion, and highlight some important subtleties in folk epistemology.

Keywords: social cognition; perception; vision; knowledge; assertion; folk epistemology

Word count: 4300

* This is the penultimate version of a paper to appear in Consciousness and Cognition. Please cite the final, published version if possible. 


\section{Introduction}

Members of many species are sensitive to another individual's gaze, which can provide useful information, such as whether the individual will approach. This has been documented in mammals, birds, reptiles, and fish (Emery 2000). Many of these animals do more than exhibit gaze sensitivity; they also follow another's gaze by looking in the same direction, which can provide useful information about food, mates, or predators. This is true of humans beginning in infancy, all the great apes, numerous other primate species, corvids, cetaceans, some domesticated mammals, and perhaps others (Shepherd 2010).

Many animals do more than just follow gaze; they also have at least some appreciation for what others can and cannot see (Senju \& Csibra 2008; Caron, Kiel, Dayton \& Butler 2002; Hare, Agnetta \& Tomasello 2000; Tomasello, Call \& Hare 1998; Okamoto-Barth, Call \& Tomasello 2007; Cheney \& Seyfarth 2007; Ruiz, Gómez, Roeder \& Byrne 2008; Amici, Aureli, Visalberghi \& Call 2009; Burkart \& Heschl 2006; Bugnyar, Schwab, Schloegl \& Kotrschal 2007; Pack \& Herman 2006). At least in corvids and primates, appreciating another's line of sight and visual access to information is connected to prediction and decision-making (Bugnyar \& Heinrich 2005; Flombaum \& Santos 2005; Maclean \& Hare 2012; Bray, Krupenye \& Hare 2014). This richer form of gaze-following is thought to be critical to the development of more sophisticated social-cognitive skills, such as joint attention, language acquisition, and mental state attribution (Flavell 1988; Baron-Cohen 1995; Tomasello 1995; Okamoto \& Tanaka 2004; Frischen, Bayliss \& Tipper 2007; Senju \& Csibra 2008). 
Humans automatically calculate what others see. From at least six years of age, we rapidly and implicitly compute what another person sees even when that information is irrelevant to the task at hand and can be ignored (Samson, Apperly, Braithwaite, Andrews \& Scott 2010; Surtees \& Apperly 2012; see also Apperly \& Butterfill 2009; Apperly 2010). This reflexive computation appears to be dissociable from more explicit and effortful mental-state attributions. Given the importance of attending to another's line of sight, it is unsurprising that it occurs rapidly and automatically and may be associated with specialized neural circuitry shared by all primates (for a review of relevant findings, see Shepherd 2010, pp. 5-6).

It is obvious that what individuals see affects what they know. This obvious truth is reflected in classic philosophical theories of knowledge (Aristotle 350 BCE/1941; Locke 1690/1975) and in the commonsense epistemology of children and adults (Pillow 1989; O'Neill, Astington \& Flavell 1992; Robinson, Thomas, Parton \& Nye 1997; Turri 2014a; Wang, Miletich, Ramsey \& Samson 2014). Moreover, explicit knowledge judgments have important social consequences, suggesting that judgments about what someone sees might have similar consequences. Research has shown that knowledge attributions affect several kinds of social evaluation, including moral judgments, decisions about whom to trust, and decisions about when others are pretending (Furrow \& Moore, 1990; Moore, Pure \& Furrow, 1990; Schroeder \& Linder 1976; Sobel 2009; Yuill \& Perner 1988). Indeed, recent results show that knowledge attributions play a uniquely powerful role in normative social cognition, influencing normative evaluations of other people more reliably than attributions of belief, evidence, or certainty (Turri in press a; Turri, Friedman \& Keefner, in press). Moreover, recent results suggest knowledge judgments mediate important ef- 
fects on how people evaluate decisions based on statistical evidence, including legal and medical decisions (Turri, Friedman \& Keefner, in press; see also Wells 1992; Dawes, Faust \& Meehl 1989).

Although prior research has studied explicit judgments about what others perceive, know, and how they should behave, these judgments have not been studied in relation to one another. For example, two recent studies compared the rate of knowledge attribution to agents who either "look carefully" or "think carefully" in response to a question (Turri 2014a; Turri 2015b). Whereas looking and thinking were viewed as equally effective in producing knowledge of affirmative propositions (i.e. that something is present or happening), looking was was viewed as more effective in producing knowledge of negative propositions (i.e. that something is not present or not happening). Another recent study investigated adults' attitudes about the relative effectiveness of different perceptual modalities to produce knowledge (Wang, Miletich, Ramsey \& Samson 2014). Reaction time data suggested that adults think that looking is more informative than either touching or lifting, even when controlling for the appropriateness of sensory modality for acquiring information. In neither of these lines of research did researchers collect judgments about perception or how the agent should act.

In this paper, I report two experiments investigating the relationship among explicit judgments about what others see, know, and should do. As far as I am aware, this is the first research to investigate these three important judgments together. This research will help address at least two connected theoretical questions.

First, some have argued that knowledge functions as the norm of our social practice of as- 
sertion (e.g. Williamson 2000; Turri 2013; Turri 2014b; see also Craig 1990). On this view, you should assert something only if you know it is true, and knowledge explains why you should make the assertion. This hypothesis about assertion is supported by observational data connecting assertion to knowledge (Turri 2011a). We can prompt an assertion by asking whether someone has knowledge (e.g. "Do you know what time it is?") (Turri 2010a); when questioned, we can abstain from making an assertion by citing lack of knowledge (e.g. "Sorry, I don't know") (Reynolds 2002). And we can challenge an assertion by referencing knowledge (e.g. "Do you really know that?" or "You don’t know what you're talking about”) (Unger 1975).

The hypothesis about assertion is also supported by experimental results. For example, in one study researchers told participants that an agent either believed a true proposition, was certain of a fact, or knew that a proposition was true. Participants who were told that the agent knew were significantly more likely to judge that the agent should make an assertion (Turri, Friedman \& Keefner under review; see also Turri in press). Another study manipulated whether participants were told that an agent either knows or does not know a proposition. The manipulation dramatically affected whether people judged that the agent should assert the proposition: people strongly judged that the agent should make the assertion when she knew, but they strongly judged that she should not make the assertion when she did not know (Turri 2015a).

Although these and other findings support the hypothesis that knowledge is the norm of assertion, an important alternative hypothesis has not been ruled out. The alternative is that assertability and knowledge have a common cause. On this view, there is no single norm of assertion. Instead, there is a variety of norms which license assertion based on information from ap- 
proved sources, such as vision and other sensory modalities, memory, testimony, and competent inference. Moreover, the alternative continues, knowledge is an additional consequence of information acquired in these ways. For example, suppose an agent looks at a scene and sees that there is a vervet monkey in the tree. In virtue of this, the agent knows that there is a vervet monkey in the tree, and the agent should tell others who are interested in this fact. If this alternative is correct, then knowledge would be a reliable sign of assertability, but it would not be the source of assertability.

Second, cases involving perception in misleading environments are often considered relevant to investigating the norm of assertion. In particular, several theorists have argued that such cases show that knowledge is not the norm of assertion (Hill \& Schechter 2007; Lackey 2007; Brown 2008; Smithies 2012; Smith 2012; Coffman 2014). According to this objection, someone who sees that there is a house is fully entitled to assert that there is a house, regardless of whether she happens to be in a highly misleading environment where most things that look like houses are not actually houses (due to, say, recent activity by a film crew constructing an elaborate outdoor set). Nevertheless, the objection continues, being in such an environment prevents the agent from knowing. If this objection is correct, then we should expect competent speakers evaluating such cases to attribute perception and assertability but deny knowledge.

\section{Preview of the experiments}

In the following experiments, participants read a short story and made judgments about what the agent sees, knows, and should say. Experiment 1 is a preliminary test of whether an object's hav- 
ing an atypical appearance affects attributions of perception, knowledge, or assertability. The typical/atypical difference, on its own, does not affect these judgments. This is important because the next experiment tests these judgments in a case that builds on the difference between typical and atypical appearances. Experiment 2 tests whether attributions of perception, knowledge, or assertability are affected by surrounding the object of interest with visibly similar items. It affects all three judgments but the central tendency is still to attribute all three qualities. In order to gain insight into the underlying psychological processes involved in making these judgments, I also use causal modeling in Experiment 2. On the best fitting causal model, knowledge attributions cause perception attributions, which in turn cause assertability attributions.

\section{Experiment 1}

The purpose of this first experiment is to determine whether people think an atypical appearance, on its own, leads to lower attributions of perception, knowledge, and assertability. This is an important preliminary step before proceeding to test a slightly more complicated case building on the difference between typical and atypical appearances.

\section{Method}

\section{Participants}

One hundred participants were tested (aged 18-62 years, mean age $=33$ years; 36 female; $96 \%$ reporting English as a native language). Participants were U.S. residents, recruited and tested on- 
line using Amazon Mechanical Turk and Qualtrics, and compensated $\$ 0.40$ for approximately 2 minutes of their time. Repeat participation was prevented. The same recruitment and compensation procedures were used for the subsequent experiment.

\section{Material and Procedure}

Participants were randomly assigned to one of two conditions, typical and atypical. All participants read a simple story, responded to three test statements, answered a comprehension check, then completed a brief demographic questionnaire. Here is the text of the story (manipulation in brackets):

(Typical/atypical) The vast majority of vervet monkeys have grey hair. It's rare, but a small percentage of vervet monkeys are born with white hair all over. This condition is known as "albinism." " $\left.\right|^{1}$ Agnes is helping a team collect data on primates in a forest habitat to help with conservation efforts. Part of this involves developing a map of how different types of monkeys are distributed throughout the forest, including which trees they tend to feed in. I While Agnes is backpacking through the forest, a vervet monkey is feeding in the tree above her. Agnes looks up and sees the vervet monkey with [grey/ white] hair in the tree.

After reading the story, participants rated their agreement with three test statements presented in a matrix table:

${ }^{1}$ Denotes a paragraph break on the participant's screen. 
1. Agnes knows that there is a vervet monkey in this tree.

2. Agnes sees that there is a vervet monkey in this tree.

3. Agnes should tell the team that there is a vervet monkey in this tree.

The order of statements was randomized. Responses were collected on a standard 7-point Likert scale, "strongly disagree" (=1) through "strongly agree" $(=7)$, left-to-right on the participant's screen. Participants then advanced to a new screen and answered the same comprehension check. It was not possible to return to a previous screen.

\section{Results}

One hundred percent of participants passed the comprehension check. There was no effect of condition on the attribution of knowledge, perception, or assertability. (See Table 1.) Mean knowledge, perception, and assertability attributions were significantly above the midpoint $(=4)$ in both conditions. (See Table 2.) Overall, mean perception attribution $(\mathrm{M}=6.55, \mathrm{SD}=0.67)$ exceeded mean knowledge attribution $(\mathrm{M}=6.20, \mathrm{SD}=1.26)$, paired samples t-test, $\mathrm{t}(99)=3.54$, $\mathrm{p}<.001, \mathrm{MD}=0.35, \mathrm{~d}=0.42$ (all reported tests two-tailed)

Table 1. Experiment 1. Independent samples t-tests.

\begin{tabular}{|c|c|c|c|c|c|c|c|}
\hline \multirow[b]{2}{*}{ Measure } & \multicolumn{2}{|c|}{ Mean (SD) } & \multirow[b]{2}{*}{$t$} & \multirow[b]{2}{*}{ df } & \multirow[b]{2}{*}{$p$} & \multirow[b]{2}{*}{ MD } & \multirow[b]{2}{*}{ d } \\
\hline & Typical & Atypical & & & & & \\
\hline Know & $6.27(1.29)$ & $6.14(1.32)$ & 0.51 & 98 & .613 & 0.13 & 0.10 \\
\hline See & $6.57(0.74)$ & $6.53(0.61)$ & 0.31 & 98 & .756 & 0.04 & 0.06 \\
\hline Should & $5.98(1.18)$ & $6.25(0.82)$ & -1.36 & 98 & .178 & -0.28 & 0.27 \\
\hline
\end{tabular}


Table 2. Experiment 1. One sample samples t-tests. Test value $=4$.

\begin{tabular}{lccccc|ccccc}
\hline & \multicolumn{9}{c}{ Typical } & \multicolumn{5}{c}{ Atypical } \\
\cline { 2 - 11 } Measure & $\mathbf{t}$ & $\mathbf{d f}$ & $\mathbf{p}$ & MD & $\mathbf{d}$ & $\mathbf{t}$ & $\mathbf{d f}$ & $\mathbf{p}$ & MD & $\mathbf{d}$ \\
\hline Know & 12.32 & 48 & $<.001$ & 2.27 & 1.76 & 12.38 & 50 & $<.001$ & 2.14 & 1.62 \\
\hdashline See & 24.46 & 48 & $<.001$ & 2.57 & 3.47 & 29.53 & 50 & $<.001$ & 2.53 & 4.18 \\
\hdashline Should & 11.73 & 48 & $<.001$ & 1.98 & 1.68 & 19.62 & 50 & $<.001$ & 2.26 & 2.76 \\
\hline
\end{tabular}

\section{Discussion}

The results indicate that, on its own, an atypical appearance does not affect people's willingness to attribute knowledge, perception, or assertability.

\section{Experiment 2}

This experiment tests whether knowledge, perception, and assertability attributions are affected when the object of interest is surrounding highly visibly similar items. I also use causal modeling to gain insight into the psychological process involved in making these attributions.

\section{Method}

\section{Participants}

Two hundred and one new participants were tested (aged 19-70 years, mean age $=32$ years; 79 female; 95\% reporting English as a native language). I tested more participants this time to ensure enough data for a causal search. 


\section{Materials and Procedure}

The materials and procedure were exactly the same as in Experiment 1, except that this time the story included an extra sentence at the very beginning, "The only visible difference between vervet monkeys and inland snow monkeys is the color of their hair," and at the end, "It is surrounded by several white snow monkeys."

\section{Results}

Ninety-seven percent of participants (194 of 201) passed the comprehension check. Assignment to condition affected response to the knowledge, perception, and assertability attributions. (See Table 3 and Fig. 1.) Mean knowledge, perception, and assertability attributions were significantly above the midpoint $(=4)$ in both conditions. (See Table 4.) Overall, mean perception attribution $(\mathrm{M}=5.85, \mathrm{SD}=1.50)$ exceeded mean knowledge attribution $(\mathrm{M}=5.45, \mathrm{SD}=1.74)$, paired samples t-test, $\mathrm{t}(193)=5.88, \mathrm{p}<.001, \mathrm{MD}=0.39, \mathrm{~d}=0.45$.

Table 3. Experiment 2. Independent samples t-tests.

\begin{tabular}{lcccccccc}
\hline & \multicolumn{2}{c}{ Mean (SD) } & & & & & \\
\cline { 2 - 4 } Measure & Typical & Atypical & & t & df & p & MD & d \\
\hline Know & $6.03(1.19)$ & $4.93(1.97)$ & 4.74 & 167.9 & $<.001$ & 1.10 & 0.73 \\
\cline { 5 - 8 } See & $6.26(0.90)$ & $5.47(1.81)$ & 3.90 & 151.3 & $<.001$ & 0.79 & 0.63 \\
\hdashline Should & $5.96(1.14)$ & $5.36(1.62)$ & 2.97 & 181.4 & .003 & 0.59 & 0.44 \\
\hline
\end{tabular}


Table 4. Experiment 2. One sample t-tests. Test value $=4$.

\begin{tabular}{|c|c|c|c|c|c|c|c|c|c|c|}
\hline \multirow[b]{2}{*}{ Measure } & \multicolumn{5}{|c|}{ Typical } & \multicolumn{5}{|c|}{ Atypical } \\
\hline & $t$ & df & p & MD & d & $t$ & df & $p$ & MD & d \\
\hline Know & 16.38 & 91 & $<.001$ & 2.03 & 1.71 & 4.74 & 101 & $<.001$ & 0.93 & 0.47 \\
\hline See & 24.09 & 91 & $<.001$ & 2.26 & 2.51 & 8.12 & 101 & $<.001$ & 1.47 & 0.81 \\
\hline Should & 16.49 & 91 & $<.001$ & 1.96 & 1.72 & 8.49 & 101 & $<.001$ & 1.36 & 0.84 \\
\hline
\end{tabular}

Knows
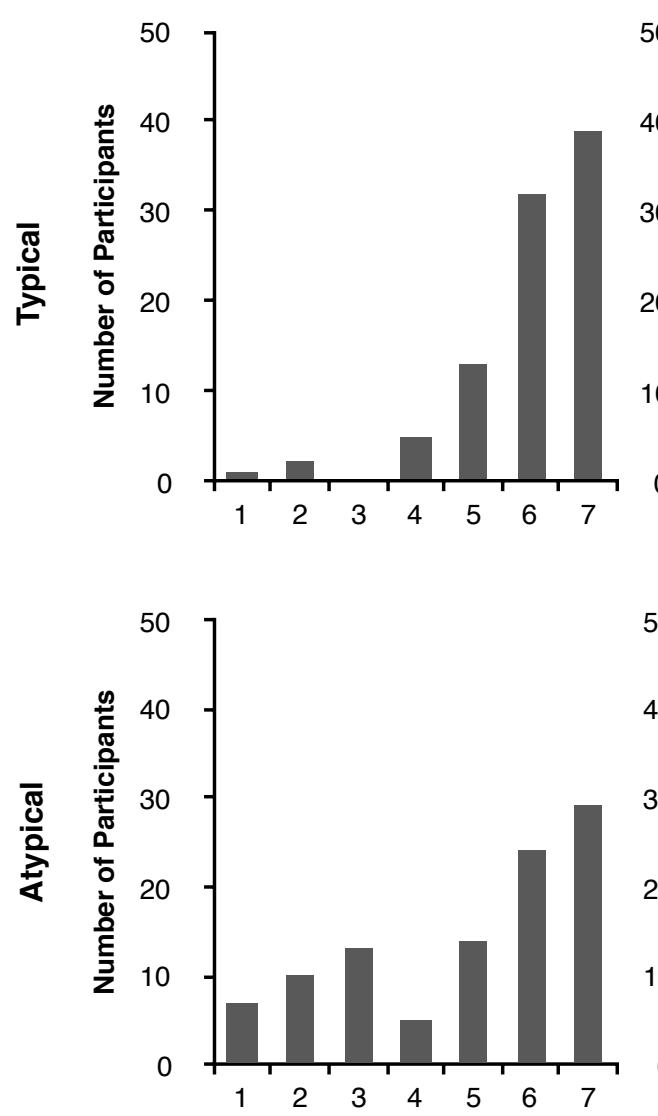

Sees
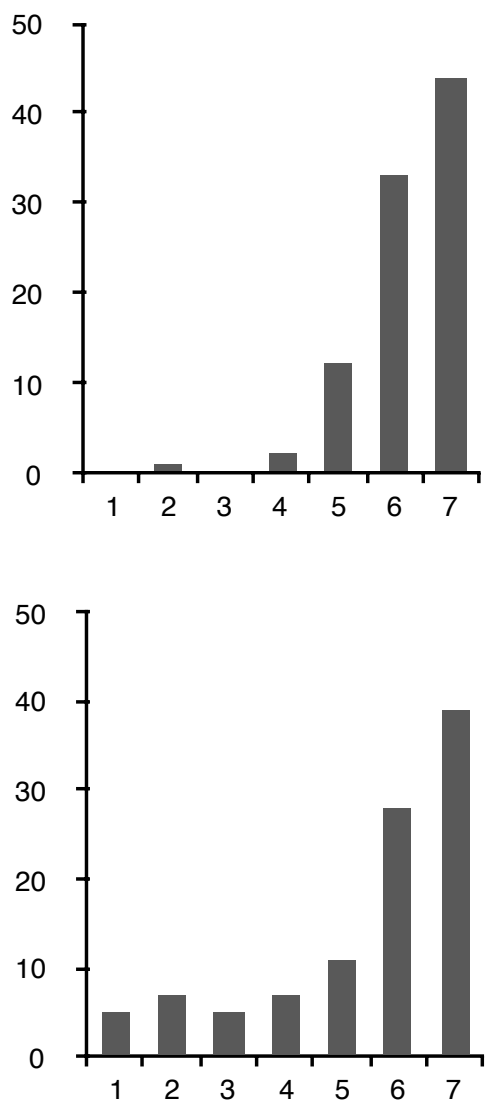

Should
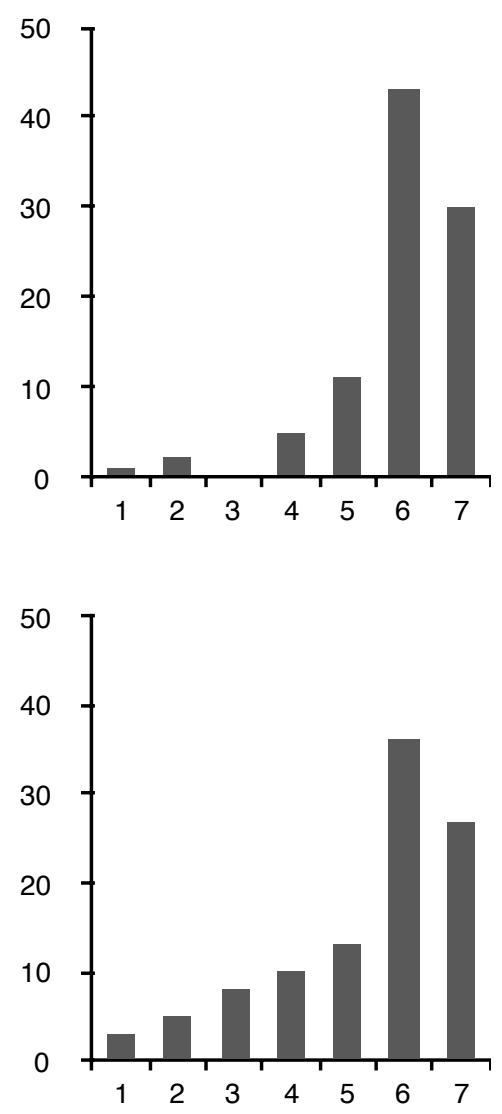

Fig. 1. Experiment 2. Distribution of responses to the knowledge and perception attributions, 1 (SD) - 7 (SA).

In order to gain insight into the underlying psychological processes involved in making 
these judgments, I conducted a causal search with with the Greedy Equivalence Search (GES) algorithm to identify the model that best fits the data. (For more on the general theory behind causal search, see Spirtes, Glymour \& Scheines 2000; Pearl 2000.) Similar to regression-based mediation analysis and structural equation modeling, GES is used to make causal inferences from correlations and independence relations in a dataset. However, GES has certain advantages. Whereas mediation analysis and structural equal modeling assume a causal direction, GES does not. GES provides an overall measure of model fit and, given enough data, will return the true causal model (Chickering 2002). And GES is not limited to considering a single pre-specified model, which typically depends on theoretical assumptions. GES considers all possible models available given the different variables. Each variable is treated as a node. GES assigns an information score to the model in which all the nodes are disconnected — the "null model." GES then evaluates adding causal arrows — "edges" — between the nodes (Meek 1997 provides the edge orientation rules). GES adds edges that best improve the model's information score, if such edges exist, until adding more edges does not improve the information score. At this point, GES evaluates whether deleting any edges will further improve the information score, and it deletes any such edges until deleting more edges does not improve the information score.

The causal search was conducted with Tetrad 5 (http://www.phil.cmu.edu/projects/tetrad/). I entered assignment to condition and response to the three dependent measures (know, see, should) into a causal search using GES. The model was constrained so that assignment to condition could not be caused by any other variable in the model. Figure 2 depicts the best fitting model, which fit the data well, $\chi^{2}(3)=2.79, \mathrm{p}=.425, \mathrm{BIC}=-13.01$. In the model, knowledge 
attributions cause perception attributions.

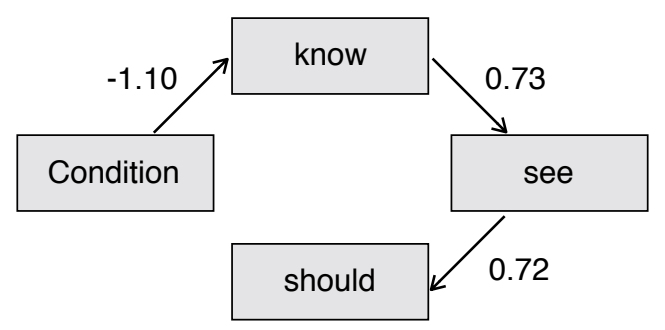

Fig. 2. Experiment 2. Causal search results. Arrows represent directional causal relations; path coefficients represent the strength of the causal relation. Reference class for condition: typical.

As a point of comparison, I constructed a structural equation model that was exactly the same as the model generated by the causal search, except with the positions of knowledge attributions and perception attributions reversed. This model was a very poor fit for the data, $\chi^{2}(3)=$ 49.28, $\mathrm{p}<.000000001, \mathrm{BIC}=33.48$.

As a further point of comparison, I constructed a structural equation model to test a version of the common cause hypothesis, whereby assignment to condition causes perception attributions, which in turn causes attributions of both knowledge and assertability. This model did not fit the data well, $\chi^{2}(3)=9.27, p=.026, \mathrm{BIC}=-6.54$.

\section{Follow-up}

One might raise two concerns about knowledge attributions in the present study. (Both concerns were raised by an anonymous referee.) First, one might ask whether participants attributed knowledge in the atypical case because they inferred that Agnes used other information to judge that it was a vervet monkey. For instance, the text mentioned information about how monkeys 
were distributed in the forest, and that the vervet monkey was feeding when Agnes looked at it. Perhaps participants assumed that Agnes was able to discriminate vervet monkeys from snow monkeys based on this other information. Second, one might ask whether participants mistakenly assumed that the final sentence, "It is surrounded by several white snow monkeys," characterized the content of Agnes's visual experience. To address these concerns, I ran a follow-up study that did not mention population distributions, did not mention feeding, and relocated the erstwhile final sentence to where it could not be read as characterizing the content of Agnes's visual experience.

Fifty-nine new participants were tested (aged 20-60 years, mean age $=33$ years; 20 female; 93\% reporting English as a native language). They were assigned to one of two conditions (typical, atypical) in a between-subjects design. Each participant read a single story then responded to the same knowledge attribution from previous experiments. Here is the story:

(Typical/atypical) The vast majority of vervet monkeys have grey hair. It's rare, but a small percentage of vervet monkeys are born with white hair all over. This condition is known as "albinism." - Agnes is helping a team collect data on primates in a forest habitat to help with conservation efforts. Part of this involves developing a map of where monkeys congregate. I While Agnes is backpacking through the forest, a vervet monkey, surrounded by several white snow monkeys, is in the tree above her. Agnes looks up and sees the vervet monkey with [grey/ white] hair in the tree.

The results for the knowledge attribution replicated those reported above. Mean knowledge 
attribution was higher in the typical case $(\mathrm{M}=6.00, \mathrm{SD}=1.37)$ than in the atypical case $(\mathrm{M}=$ $5.10, \mathrm{SD}=1.76)$, independent samples t-test, $\mathrm{t}(57)=2.19, \mathrm{p}=.033, \mathrm{MD}=0.90, \mathrm{~d}=0.58$. Mean knowledge attribution exceeded the neutral midpoint $(=4)$ in both conditions: typical, $t(29)=$ 8.03, $\mathrm{p}<.001, \mathrm{MD}=2.00, \mathrm{~d}=1.46$; atypical, $\mathrm{t}(28)=3.38, \mathrm{p}=.002, \mathrm{MD}=1.10, \mathrm{~d}=0.63$. These results rule out both concerns about Experiment 2.

\section{Discussion}

When an object was described as visibly indistinguishable from nearby objects, it decreased the extent to which people judged that the agent, sees, knows, and should tell others that the object is present. Nevertheless, people still tended to agree that the agent sees, knows, and should tell others that the object is present. Results from causal modeling also suggest a specific model for the cognitive processes involved in making judgments: people first make a knowledge attribution, which then informs a perception attribution, which then informs an assertability attribution. (Note that this is a model of the cognitive process involved in making these attributions explicitly; see the General Discussion for further discussion.) As in Experiment 1, perception attributions tended to be higher than knowledge attributions.

\section{General Discussion}

Two experiments investigated the relationship among explicit judgments about what people see, know, and should say. The mere fact that an object presents an atypical appearance affected nei- 
ther perception attributions (the agent sees that something is the case), knowledge attributions (the agent knows that it is the case), nor assertability attributions (the agent should tell others that it is the case) (Experiment 1). When the object of interest was surrounded by visibly similar items, it diminished people's willingness to attribute perception, knowledge, and assertability; however, the clear central tendency was still to attribute all three qualities (Experiment 2). Causal modeling suggested a specific psychological model of how these three judgments are made: knowledge attributions cause perception attributions, which in turn cause assertability attributions (Experiment 2). Taken together, these findings contribute to knowledge of how these three important judgments are made.

The findings also shed light on other important questions. An impressive case has recently been built that knowledge is the norm of assertion (for a state-of-the-art presentation, see Turri in press b). According to this view, you should assert something only if you know it is true, and knowledge explains why you should make the assertion. However, prior research has not ruled out an alternative explanation of the evidence. On this alternative, knowledge does not explain assertability; instead, knowledge and assertability have a common cause. For example, in cases where you acquire information visually, perhaps this explains both why you know the information and why you should provide it to interested parties. The present results provide some evidence against this alternative account. In particular, the causal modeling results suggest that the alternative does not fit the way we actually make these normative judgments. Judgments about knowledge and assertability did not have a common cause in judgments about perception.

One striking fact about the causal modeling results is that, if they are accurate, knowledge 
attributions cause perception attributions. This reverses the order explanation of how cognition actually occurs - the explanation for why the agent knows is that she sees, not vice versa. However, the causal modeling results do not conflict with this view of how cognition actually occurs. For the model in question pertains to the psychological process leading to explicit judgments about knowledge and perception. It is not a model of how knowledge and perception are in fact related. Nor does the model rule out that explicit knowledge attributions are caused by implicit representations of the agent's perceptions or access to visual information, which occur rapidly and automatically (Apperly \& Butterfill 2009; Apperly 2010).

One possibility for explaining the causal modeling results is that people think through the scenario dialectically with the agent's practical situation in mind. The agent is tasked with gathering information and sharing it with others and asserting it is the typical way to share it. Because knowledge is the norm of assertion, people are initially concerned with whether she knows that the information is true, and they form an explicit judgment about this first. Then people form an explicit judgment about how she knows, in anticipation of the familiar conversational challenge to an assertion, "How do you know that?" Finally, once it is clear whether the agent passes the typical conversational heuristic for assertability, people form an explicit judgment about assertability.

The present findings conflict with some influential philosophical theories of knowledge. These theories are based on the assumption that in situations where an agent looks at an object surrounded by visibly similar items, the obvious verdict is that the agent does not know that the object is present (e.g. Goldman 1976; Chisholm 1989, p. 93; Sosa 1991, pp. 238-9; Pritchard 
2005, pp. 161-2; Pritchard 2014, ch. 6; Greco 2010, pp. 76-80; Littlejohn 2014; for dissenting views, see Lycan 2006 and Turri 2011b). For example, Goldman's influential "relevant alternatives" theory of knowledge is motivated by the claim that people are "strongly inclined" to not attribute knowledge to such agents (Goldman 1976, p. 772-3). Goldman supports his theory by arguing that it explains this behavioral tendency. Similarly, Pritchard defends an "anti-luck" theory of knowledge on the grounds that it explains the intuition that knowledge is lacking in such cases (Pritchard 2012). However, in Experiment 2 the clear central tendency was to attribute knowledge in such a case. This agrees with results from other recent studies, which also found that people tend to attribute knowledge in similar cases (Turri, Buckwalter \& Blouw 2014; Colaço, Buckwalter, Stich \& Machery 2014). The present findings add to our understanding of these issues by demonstrating that this pattern persists when knowledge attributions occur in a more complex set of tasks, and by demonstrating that people are strongly inclined to attribute perception and assertability in the same context. Moreover, the present findings go beyond previous findings in an interesting way. Previous studies described the object of interest as inhabiting a general environment where many visibly similar items were present. But previous studies did not describe the object of interest as being "surrounded by" visibly similar items at the time of inspection. By contrast, in Experiment 2, the object of interest was described as being "surrounded by" visibly similar items, thus further demonstrating the robustness of this pattern of knowledge attribution.

Finally, the present findings suggest an interesting subtlety in commonsense epistemology. In all of the scenarios tested, the agent "looks up into a tree and sees a vervet monkey." (Partici- 
pants who failed a comprehension question related to this were excluded from the analysis.) Participants always tended to judge that the agent sees that there is a vervet monkey in the tree. Nevertheless, subtle details of the case affected how confidently and consistently people make this judgment. In particular, the presence of visibly similar items decreased this judgment. Thus, in commonsense epistemology, it might not be an automatic inference from seeing the object that is there to seeing that the object is there. This corresponds to a distinction made in the philosophical literature between "simple seeing" and "propositional seeing," according to which the former is not sufficient for the latter (Turri 2010b, p. 200; for earlier statements of the same basic idea, see Dretske 1969; Audi 1998, p. 15; see French 2013 for discussion of further views). Of course, we would expect this inference to fail when it comes to unfamiliar objects that the agent is unable to categorize, or if the agent is dazed and confused. But neither of these things is plausibly true of the scenarios tested here, nor could they explain the differences across conditions, because they do not change across conditions.

Acknowledgments - For helpful comments and feedback, I thank Wesley Buckwalter, Fiery Cushman, Clayton Littlejohn, Jonathan Phillips, David Rose, Laurie Santos, and Angelo Turri. Thanks also to an audience at the 2014 Primate Epistemology Workshop at Yale University. This research was supported by the Social Sciences and Humanities Research Council of Canada and an Early Researcher Award from the Ontario Ministry of Economic Development and Innovation. 


\section{References}

Amici, F., Aureli, F., Visalberghi, E., \& Call, J. (2009). Spider monkeys (Ateles geoffroyi) and capuchin monkeys (Cebus apella) follow gaze around barriers: Evidence for perspective taking? Journal of Comparative Psychology, 123(4), 368. doi:10.1037/a0017079

Apperly, I. A. (2010). Mindreaders: the cognitive basis of "theory of mind." Hove, UK: Psychology Press.

Apperly, I. A., \& Butterfill, S. A. (2009). Do humans have two systems to track beliefs and belief-like states? Psychological Review, 116(4), 953-970. doi:10.1037/a0016923

Aristotle. (1941). Posterior analytics. In R. McKeon (Ed.), G. R. G. Mure (Trans.), The basic works of Aristotle. New York: Random House.

Audi, R. (1998). Epistemology: a contemporary introduction to the theory of knowledge. New York: Routledge.

Baron-Cohen, S. (1995). The eye direction detector (EDD) and the shared attention mechanism (SAM): two cases for evolutionary psychology. In C. Moore \& P. J. Dunham (Eds.), Joint attention: its origins and role in development (pp. 41-59). Hillsdale, NJ: Erlbaum.

Bray, J., Krupenye, C., \& Hare, B. (2014). Ring-tailed lemurs (Lemur catta) exploit information about what others can see but not what they can hear. Animal Cognition, 17, 735-744.

Brown, J. (2008). The knowledge norm for assertion. Philosophical Issues, 18, 89-103.

Bugnyar, T., \& Heinrich, B. (2005). Ravens, Corvus corax, differentiate between knowledgeable and ignorant competitors. Proceedings of the Royal Society B: Biological Sciences, 
272(1573), 1641-1646. doi:10.1098/rspb.2005.3144

Bugnyar, T., Schwab, C., Schloegl, C., \& Kotrschal, K. (2007). Ravens Judge Competitors through Experience with Play Caching. Current Biology.

Burkart, J., \& Heschl, A. (2006). Geometrical gaze following in common marmosets (Callithrix jacchus). Journal of Comparative Psychology, 120(2), 120. doi: $10.1037 / 0735-7036.120 .2 .120$

Caron, A. J., Kiel, E. J., Dayton, M., \& Butler, S. C. (2002). Comprehension of the Referential Intent of Looking and Pointing Between 12 and 15 Months. Journal of Cognition and Development, 3(4), 445-464. doi:10.1080/15248372.2002.9669677

Cheney, D. L., \& Seyfarth, R. M. (2007). Baboon metaphysics: the evolution of a social mind. Chicago: University of Chicago PressChicago, IL.

Chickering, D. M. (2002). Optimal structure identification with greedy search. The Journal of Machine Learning Research, 3(1), 507-554. doi:10.1109/69.494161

Chisholm, R. (1989). Theory of Knowledge (3rd ed.). Englewood Cliffs, NJ: Prentice Hall.

Coffman, E. J. (2014). Lenient accounts of warranted assertability. In C. Littlejohn \& J. Turri (Eds.), Epistemic norms: new essays on action, belief and assertion (pp. 33-59). Oxford University press.

Colaço, D., Buckwalter, W., Stich, S., \& Machery, E. (2014). Epistemic intuitions in fake-barn thought experiments. Episteme, 11(02), 199-212. doi:10.1017/epi.2014.7

Craig, E. (1990). Knowledge and the state of nature: an essay on conceptual synthesis. Oxford: Oxford University Press. 
Dawes, R., Faust, D., \& Meehl, P. (1989). Clinical versus actuarial judgment. Science, 243(4899), 1668-1674. doi:10.1126/science.2648573

Dretske, F. I. (1969). Seeing and knowing. London: Routledge \& Kegan Paul.

Emery, N. J. (2000). The eyes have it: the neuroethology, function and evolution of social gaze. Neuroscience \& Biobehavioral Reviews, 24(6), 581-604. doi:10.1016/ S0149-7634(00)00025-7

Flavell, J. H. (1988). The development of children's knowledge about the mind: from cognitive connections to mental representations. In J. Astington, P. Harris, \& D. Olson (Eds.), Developing theories of mind (pp. 244-267). New York: Cambridge University Press.

Flombaum, J. I., \& Santos, L. R. (2005). Rhesus Monkeys Attribute Perceptions to Others. Current Biology, 15(5), 447-452. doi:10.1016/j.cub.2004.12.076

French, C. (2013). Perceptual experience and seeing that P. Synthese, 190(10), 1735-1751. doi: $10.1007 / \mathrm{s} 11229-013-0259-3$

Frischen, A., Bayliss, A. P., \& Tipper, S. P. (2007). Gaze cueing of attention: Visual attention, social cognition, and individual differences. Psychological Bulletin, 133(4), 694. doi: 10.1037/0033-2909.133.4.694

Furrow, D., \& Moore, C. (1990). Gender differences in differentiating terms expressing certainty. Journal of Psycholinguistic Research, 19(6), 375-385. doi:10.1007/BF01068885

Goldman, A. I. (1976). Discrimination and perceptual knowledge. Journal of Philosophy, 73(20), $771-791$.

Greco, J. (2010). Achieving knowledge: A virtue-theoretic account of epistemic normativity. 
Cambridge: Cambridge University Press.

Hare, B., Call, J., Agnetta, B., \& Tomasello, M. (2000). Chimpanzees know what conspecifics do and do not see. Animal Behaviour, 59(4), 771-785. doi:10.1006/anbe.1999.1377

Hill, C., \& Schechter, J. (2007). Hawthorne's lottery puzzle and the nature of belief. Philosophical Issues, 17, 102-122.

Lackey, J. (2007). Norms of assertion. Nous, 41(4), 594-626.

Littlejohn, C. (2014). Fake barns and false dilemmas. Episteme, 11(04), 369-389. doi:10.1017/ epi.2014.24

Locke, J. (1975). An essay concerning human understanding. (P. H. Nidditch, Ed.). Oxford: Clarendon Press.

Lycan, W. G. (2006). The Gettier problem problem. In S. Hetherington (Ed.), Epistemology futures (pp. 148-168). Oxford: Oxford University Press.

MacLean, E. L., \& Hare, B. (2012). Bonobos and chimpanzees infer the target of another's attention. Animal Behaviour, 83(2), 345-353. doi:10.1016/j.anbehav.2011.10.026

Meek, C. (1997). Graphical models: selecting causal and statistical models. Carnegie Mellon University.

Melis, A. P., Call, J., \& Tomasello, M. (2006). Chimpanzees conceal visual and auditory information from others. Journal of Comparative Psychology, 120(2), 154. doi:10.1037/07357036.120 .2 .154

Moore, C., Pure, K., \& Furrow, D. (1990). Children's Understanding of the Modal Expression of Speaker Certainty and Uncertainty and Its Relation to the Development of a Representa- 
tional Theory of Mind. Child Development, 61(3), 722-730. doi:10.1111/j. 1467-8624.1990.tb02815.x

O'Neill, D. K., Astington, J. W., \& Flavell, J. H. (1992). Young Children's Understanding of the Role That Sensory Experiences Play in Knowledge Acquisition. Child Development, 63(2), 474-490. doi:10.1111/j.1467-8624.1992.tb01641.x

Okamoto, S., \& Tanaka, M. (2004). Looking back: The "representational mechanism" of joint attention in an infant chimpanzee (Pan troglodytes). Japanese Psychological Research, 46(3), 236-245.

Okamoto-Barth, S., Call, J., \& Tomasello, M. (2007). Great apes“ understanding of other individuals" line of sight. Psychological Science, 18(5), 462-468.

Pack, A. A., \& Herman, L. M. (2006). Dolphin Social Cognition and Joint Attention: Our Current Understanding. Journal of Applied Behavioral Science, 32(4), 443-460. doi:10.1578/ AM.32.4.2006.443

Pearl, J. (2000). Causality: models, reasoning, and inference. Cambridge: Cambridge University Press.

Pillow, B. H. (1989). Early understanding of perception as a source of knowledge. Journal of Experimental Child Psychology, 47(1), 116-129. doi:10.1016/0022-0965(89)90066-0

Pritchard, D. (2005). Epistemic luck. New York : Oxford University Press.

Pritchard, D. (2012). Anti-luck virtue epistemology. Journal of Philosophy, 109(3), 247-279.

Pritchard, D. (2014). Epistemic luck, safety, and assertion. In C. Littlejohn \& J. Turri (Eds.), Epistemic norms: new essays on action, belief and assertion. Oxford: Oxford University 
Press.

Reynolds, S. L. (2002). Testimony, knowledge, and epistemic goals. Philosophical Studies, 110(2), 139-161.

Robinson, E. J., Thomas, G. V., Parton, A., \& R, N. (1997). Children's overestimation of the knowledge to be gained from seeing. British Journal of Developmental Psychology, 15, $257-273$.

Ruiz, A., Gómez, J. C., Roeder, J. J., \& Byrne, R. W. (2008). Gaze following and gaze priming in lemurs. Animal Cognition, 12(3), 427-434. doi:10.1007/s10071-008-0202-z

Samson, D., Apperly, I. A., Braithwaite, J. J., Andrews, B. J., \& Bodley Scott, S. E. (2010). Seeing it their way: Evidence for rapid and involuntary computation of what other people see. Journal of Experimental Psychology: Human Perception and Performance, 36(5), 1255. doi:10.1037/a0018729

Schroeder, D. A., \& Linder, D. E. (1976). Effects of actor's causal role, outcome severity, and knowledge of prior accidents upon attributions of responsibility. Journal of Experimental Social Psychology, 12(4), 340-356.

Senju, A., \& Csibra, G. (2008). Gaze Following in Human Infants Depends on Communicative Signals. Current Biology.

Shepherd. (2010). Following gaze: gaze-following behavior as a window into social cognition. Frontiers in Integrative Neuroscience. doi:10.3389/fnint.2010.00005

Smith, M. (2012). Some Thoughts on the JK-Rule. Nous, 46(4), 791-802.

Smithies, D. (2012). The Normative Role of Knowledge. Nous, 46(2), 265-288. doi:10.1111/j. 
1468-0068.2010.00787.x

Sosa, E. (1991). Knowledge in Perspective. Cambridge: Cambridge University Press.

Spirtes, P., Glymour, C. \& Scheines, R. (2000). Causation, prediction, and search (2ed.). Cambridge, Mass.: MIT Press.

Surtees, A., Apperly, I. A., \& Samson, D. (2013). Similarities and differences in visual and spatial perspective-taking processes. Cognition, 129(2), 426-438. doi:10.1016/j.cognition. 2013.06.008

Tomasello, M. (1995). Joint attention as social cognition. In C. Moore \& P. J. Dunham (Eds.), Joint attention: its origins and role in development (pp. 103-130). Hillsdale, NJ: Erlbaum.

Tomasello, M., Call, J., \& Hare, B. (1998). Five primate species follow the visual gaze of conspecifics. Animal Behaviour, 55(4), 1063-1069. doi:10.1006/anbe.1997.0636

Turri, J. (2010a). Prompting challenges. Analysis, 70(3), 456-462. doi:10.1093/analys/anq027

Turri, J. (2010b). Does perceiving entail knowing? Theoria, 76, 197-206. doi:10.1111/j. 1755-2567.2010.01065.x

Turri, J. (2011a). The express knowledge account of assertion. Australasian Journal of Philosophy, 89(1), 37-45. doi:10.1080/00048401003660333

Turri, J. (2011b). Manifest failure: the Gettier problem solved. Philosophers' Imprint, 11(8), 111.

Turri, J. (2013). The test of truth: An experimental investigation of the norm of assertion. Cognition, 129(2), 279-291. doi:10.1016/j.cognition.2013.06.012 
Turri, J. (2014a). Skeptical Appeal: The Source-Content Bias. Cognitive Science, n/a-n/a. doi: $10.1111 / \operatorname{cogs} .12153$

Turri, J. (2014b). Knowledge and suberogatory assertion. Philosophical Studies, 167(3), 557567. doi:10.1007/s11098-013-0112-z

Turri, J. (2015a ). Knowledge and the norm of assertion: a simple test. Synthese, 192(2), 385392. doi:10.1007/s11229-014-0573-4

Turri, J. (2015b). An open and shut case: epistemic closure in the manifest image. Philosophers'Imprint.

Turri, J. (in press a). Knowledge, certainty and assertion. Synthese.

Turri, J. (in press b). Knowledge and the norm of assertion: an essay in philosophical science. Open Book Publishers.

Turri, J., Buckwalter, W., \& Blouw, P. (2014). Knowledge and luck. Psychonomic Bulletin \& Review. doi:10.3758/s13423-014-0683-5

Turri, J., Friedman, O., \& Keefner, A. (in press). Knowledge central: a central role for knowledge attributions in social evaluations. Quarterly Journal of Experimental Psychology.

Unger, P. (1975). Ignorance: a case for skepticism. Oxford: Oxford University Press.

Wang, J. J., Miletich, D. D., Ramsey, R., \& Samson, D. (2014). Adults see vision to be more informative than it is. Quarterly Journal of Experimental Psychology, 67(12), 2279-2292. doi:10.1080/17470218.2014.915331

Wells, G. L. (1992). Naked statistical evidence of liability: Is subjective probability enough? Journal of Personality and Social Psychology, 62(5), 739. doi: 
10.1037/0022-3514.62.5.739

Whiten, A. (2013). Humans are not alone in computing how others see the world. Animal Behaviour, 86(2), 213-221. doi:10.1016/j.anbehav.2013.04.021

Williamson, T. (2000). Knowledge and its limits. Oxford: Oxford University Press. 